NASA Technical Memorandum 106139

$1 N-20$

$\ldots-163059$

\title{
Nuclear Electric Propulsion for Planetary Science Missions: NASA Technology Program Planning
}

Michael P. Doherty

Lewis Research Center

Cleveland, Ohio

Prepared for the

Tenth Symposium on Space Nuclear Power and Propulsion

sponsored by The University of New Mexico and The American Institute of Physics

Albuquerque, New Mexico, January 10-14, 1993

(NASA-TM-106139) NUCLEAR ELECTRIC PROPULSION FOR PLANETARY SCIENCE MISSIONS: NASA TECHNOLOGY PROGRAM 


\title{
NUCLEAR ELECTRIC PROPULSION \\ FOR PLANETARY SCIENCE MISSIONS: \\ NASA TECHNOLOGY PROGRAM PLANNING
}

\author{
Michael P. Doherty \\ NASA Lewis Research Center \\ 21000 Brookpark Rd. \\ Cleveland, $\mathrm{OH} 44135$
}

(216) $977-7092$

\begin{abstract}
This paper presents the status of technology program planning to develop those Nuclear Electric Propulsion technologies needed to meet the advanced propulsion system requirements for planetary science missions in the next century. The technology program planning is based upon tecbnologies with significant development heritage: ion electric propulsion and the SP-100 space nuclear power technologies. Detailed plans are presented herein for the required ion electric propulsion technology development and demonstration. Closer coordination between space nuclear power and space electric propulsion technology programs is a necessity as technology plans are being further refined in light of NEP concept definition and possible early NEP flight activities.
\end{abstract}

\section{BACKGROUND}

The Solar System Exploration Division of the NASA's Office of Space Science and Applications (OSSA) foresees a need for low thrust Nuclear Electric Propulsion (NEP) to provide a large reduction in propellant mass, to allow for launch date flexibility, and to reduce trip times for science missions to many planetary, asteroidal, and cometary

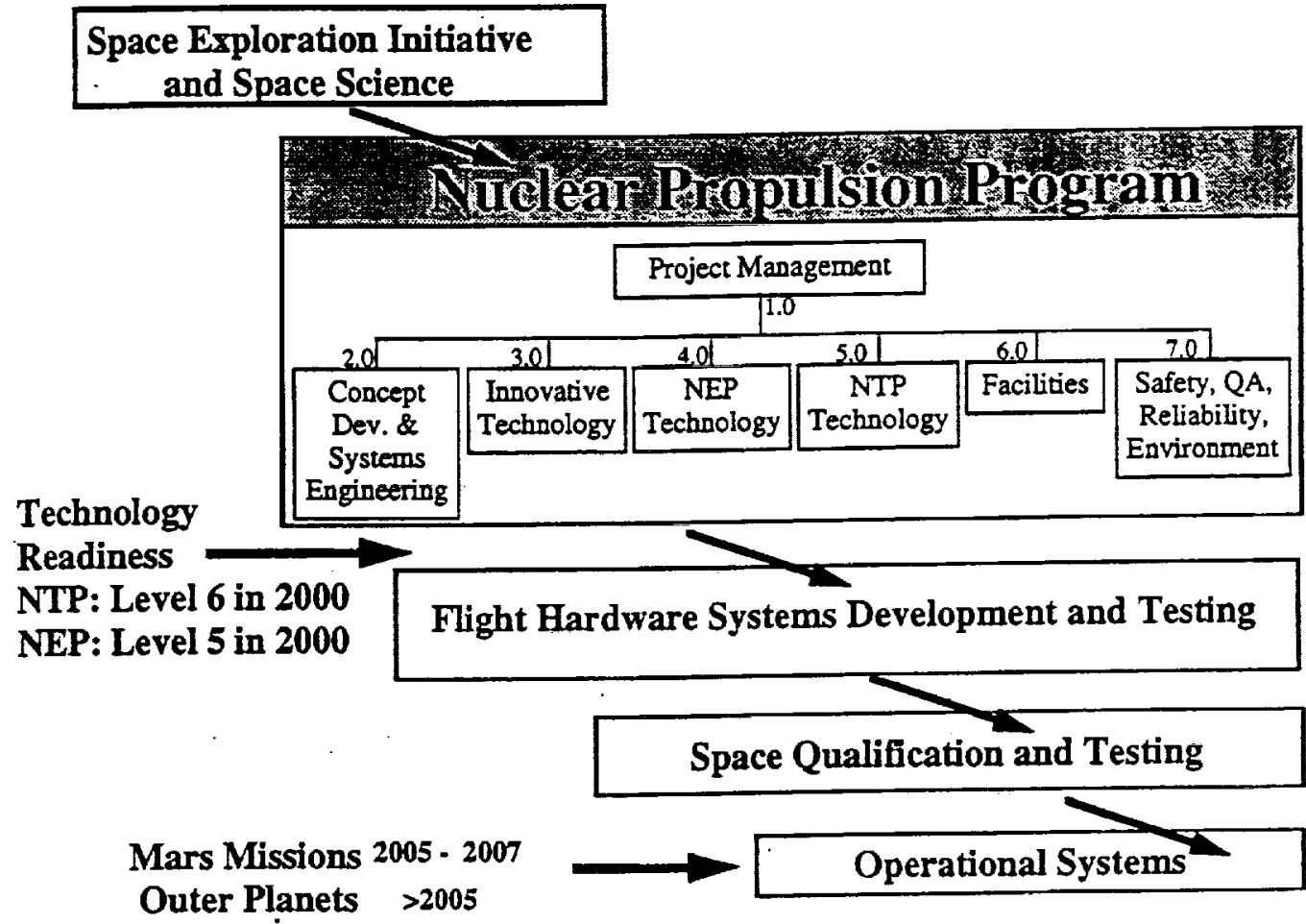

FIGURE-1. Logic Flow for Nuclear Propulsion. 
targets. Mission and system studies, assuming the use of SP-100 (reactor and power conversion) technology and ion electric propulsion, have been performed which show that NEP enables a number of the proposed missions, allows for orbiter missions to the major satellites of Jupiter, Uranus, Neptune, and Pluto (versus flybys), and yields more frequent launch opportunities (Yen and Sauer 1991). The requirements for a long life, low mass nuclear power source and efficient, long life ion electric engines provide the driver for related power and propulsion technology programs.

\section{TECHNOLOGY PROGRAM PLANS}

A logic flow path for Nuclear Propulsion and its development has been established (Bennett and Miller 1992). Figure 1 figuratively conveys this logic flow path, showing that a Nuclear Propulsion Program is responsive to advanced propulsion requirements for space exploration and space science and enables flight hardware systems development. The purpose of the Nuclear Propulsion Program is to develop and demonstrate focused nuclear propulsion systems technology including compliance with sound safety and environmental policies that meet space exploration and space science mission requirements.

\section{Baseline Focused Technology Efforts}

A preliminary overall schedule for the development of 100-kilowatt (kWe) NEP for outer planetary science missions is shown in Figure 2. The required development steps are Focused Technology, System Definition, Advanced Development, and Flight System Development. This schedule shows that the authority to proceed with flight system development would occur approximately at the time that component level testing is complete - mid program year (PY) 1997 - and that the flight system critical design review would occur shortly after power/ propulsion technology is ready in PY2000. Work is already in progress as of PY1992 in both power and propulsion focused technology areas. In the propulsion technology area, initial plans have been established by NASA Lewis Research Center's (LeRC's) Nuclear Propulsion Office (NPO) for the development and demonstration of an electric propulsion thrust system. This activity is the chief technology focus of the Nuclear Electric Propulsion Project, serving to bring thrust system and component technologies to Technology Readiness Level 5 (TRL-5) and to verify

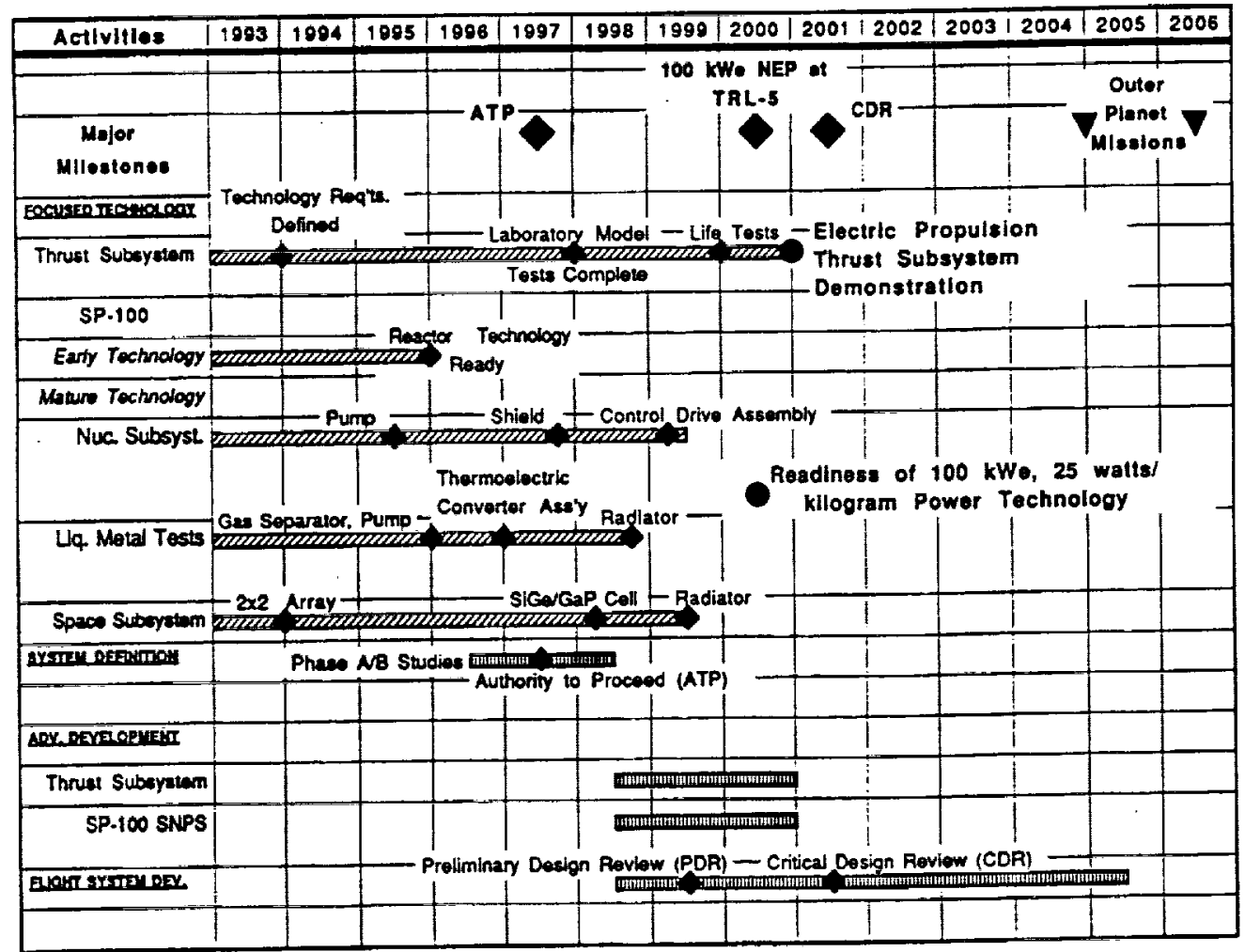

FIGURE 2. Schedule for the Development of NEP for

Outer Planetary Science Missions (Preliminary). 
analytical tools (including performance and life models) by PY2000 for outer planetary robotic missions. In tandem with this activity it will be necessary to continue development and demonstration of space nuclear power system technologies having promise to nominally provide 100 kilowatts of power at a specific power of 25 watts per kilogram. The SP-100 program has technical plans to develop and demonstrate space rated nuclear power technologies to meet these requirements by approximately the year 2000 (Armijo 1992). Milestones associated with the SP-100 technology tentatively include: (1) space nuclear reactor technology to support an early flight of NEP at a sub 50-kWe power rating, to demonstrate nuclear power system launchability and integrated operations with an electric propulsion subsystem, and (2) follow-on component and subsystem level ground tests to demonstrate power system technologies not tested in the early flight, but still necessary for 100-kWe, 25-watts-per-kilogram space nuclear power applications.

This paper will discuss the elements of the Nuclear Electric Propulsion Project, including NEP system definition and electric propulsion thrust system technology planning. The space nuclear power system technology is to be provided by the SP-100 Project.

\section{Nuclear Electric Propulsion Project}

The Nuclear Electric Propulsion Project includes six elements: project management, concept development systems engineering, NEP technology, megawatt (MW)/ innovative technology, facilities, and safety/ reliability/ quality assurance/ environment. A basic description of the scope of each of these project elements has been previously stated (Doherty 1991).

With the establishment in PY1992 of the outer planetary science propulsion application as the primary emphasis of the NEP Project, project elements and activities reflect a change in focus compared to the project originally described by Doherty (1991). The concept development/ systems engineering element will serve to document OSSA customer system requirements for NEP, define NEP systems which meet OSSA customer requirements, and design, fabricate, and test the required $100 \mathrm{kWe}$ electric propulsion thrust system. The NEP technology element will serve to design, verify, and validate the performance and life of component technologies for electric thrusters, power processors, and their required thermal subsystems. The MW/ innovative technology element will now serve to identify technologies having benefit for higher power Moon and Mars NEP applications and to perform fundamental MW technology demonstration tests. The facilities element will serve to identify and advocate the facility infrastructure that is necessary for testing of kilowatt-rated non-nuclear technologies for NEP. The safety/ reliability/ quality assurance/ environment element will serve to perform studies and assessments to establish requirements upon the safe, environmentally acceptable design, development, test, deployment, and operations of space nuclear electric propulsion.

The schedule for the Nuclear Electric Propulsion Project (Figure 3) shows extensive interaction between the project elements just described.

\section{Concept Development/ Systems Engineering}

The Concept Development Systems Engineering element will define, design, and develop the system concept which meets the propulsion requirements of the mission. This element is characterized by three chief activities. The first activity is the development and documentation of NEP system requirements. NEP system requirements to meet the propulsion requirements for the OSSA outer planetary science missions bave already been documented (NPO 1992). This document, conforming to MIL-STD-490A, describes the NEP system, states specific performance requirements, defines the approach to verification, and includes reference mission descriptions. It is meant to be a "living document", a document whose continual updating is encouraged and controlled by a formal change control process.

The second activity is the definition of a system concept to meet the propulsion requirements for the outer planetary missions. First, an assessment will be made of the applicability of a common NEP flight system in meeting the propulsion requirements of a number of the outer planetary missions, and a baseline system configured. Then, a more detailed system concept definition will be performed, which shall include consideration of thrust axis 


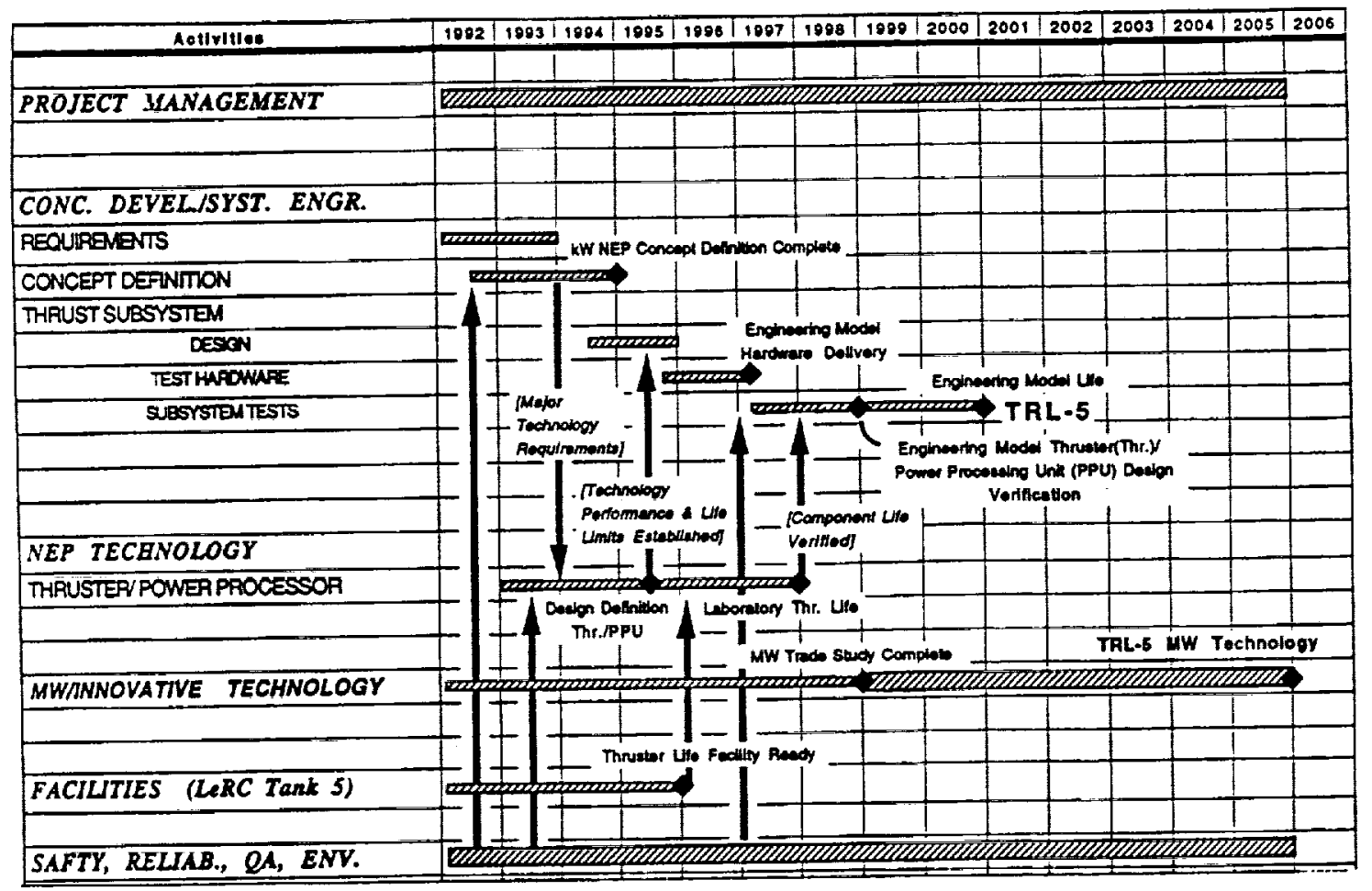

FIGURE 3. Schedule for the Nuclear Electric Propulsion Project.

orientation, nuclear electric power subsystem configuration, thruster nominal power level and array definition, thrust vectoring strategy, vehicle guidance, navigation, and control, reaction control system, telecommunications, and launch packaging and deployment. The output from this detailed definition will be the documentation of technology requirements for the space nuclear electric power system and detailed technology requirements for thruster and power processor (and associated thermal management subsystems), as well as detailed system and subsystem drawings/ schematics. Significantly detailed system and subsystem performance computer models will suppor the definition of the concept. It is expected that the initial concept definition activity (PY1993) will provide a set of major technology requirements, while the detailed system concept definition will update these technology requirements (PY1994).

The final major activity under this element is the design, hardware fabrication, and testing for the electric propulsion thrust system. Once the overall system concept is defined (PY1994) and thruster and power processor technology performance limits and life estimates are established (mid PY1995), a detailed design of the electric propulsion thrust system will be performed on contract. This will enable fabrication and delivery by industry to the government of engineering model thruster, power processor, and propellant feed system hardware (early PY1997). Subsequent to component integration and critical interface verification, a series of plume and fields compatibility, simulated qualification, and cluster tests, as well as subsystem performance (PY1998) and life verification tests (PY2000), will be performed in government space environment simulation facilities. TRL-5 (PY2000) of the electric propulsion thrust system will be supported with documentation in the form of drawing packages, assembly procedures, assembly records, and reports.

\section{NEP Technology}

The NEP Technology element will experimentally evaluate thrust subsystem components and related technologies to enable industry to develop an engineering model thrust subsystem. Technology requirements for thruster, power processor, and their related thermal management subsystems will provide focus for the required technology efforts. For thrusters, experimental evaluation of performance and life issues will require $25-50 \mathrm{~kW}$ class laboratory model 
thruster development and testing, hollow cathode, ion optics, and isolator/ neutralizer component development and demonstration, and thruster wear/ life testing. The laboratory class hardware will be used to verify critical interfaces and assess plume/ fields compatibility issues also. Models for performance and life will be developed, and then verified with the lab-class hardware. Technology performance and life limits will be established (mid PY1995), enabling the development of engineering model thrust subsystem hardware, and thruster lifetime will be demonstrated and verified (PY1997). Recent progress in non-nuclear NEP technologies has been documented by Stone and Sovey (1992).

\section{MW/ Innovative Technology}

The MW/ Innovative Technology element will serve to identify and provide requirements for technologies highly beneficial to megawatt NEP applications for the Space Exploration Initiative, and to conduct fundamental component/ subsystem performance tests.

\section{Facilities}

Long term life testing of laboratory class ion electric thrusters as well as thruster-cluster system demonstrations place a demanding set of requirements on space environment simulation facilities. The capabilities of many large U.S. vacuum chambers have been reviewed and compared with the requirements for electric propulsion testing by Sovey et al (1991). The Electric Propulsion Laboratory's Tank 5 (NASA Lewis Research Center) is a potential facility for testing the electric propulsion technologies required for 100-kWe NEP, but some facility modifications will be required by PY 1995 to enable laboratory model life testing and eventual engineering model thrust system testing. The Facilities element will provide requirements to belp ensure that the necessary facilities are available for electric propulsion component, subsystem, and full system ground testing.

\section{Safety/ Reliability/ Quality Assurance/ Environment}

System safety, reliability, quality assurance, and environmental impact assessments will have continual impact on concept definition, component technology evaluation, and thrust system design and design verification activities.

\section{IMPLICATIONS OF AN EARLY FLIGHT OF NEP}

As a consequence of the signing of a Memorandum of Understanding Between NASA and the Department of Energy (DOE) regarding energy-related civil space activities (July 9, 1992), a working group was established to consider program options for a small, lightweight, compact nuclear reactor sized to meet NASA proposed space, and lunar, and planetary surface programs (Greene 1992). The working group's highest consideration for such a compact nuclear reactor is a liquid metal cooled, fuel pin, fast spectrum reactor with a Brayton power conversion system rated nominally at $20-\mathrm{kWe}$, and mated with an electric propulsion subsystem into an NEP flight system for several planetary science missions (Greene and Newhouse 1992). The mission application of such an early flight option for NEP has been reviewed with the Solar System Exploration Division, and fundamental agreement obtained that this early NEP flight option should be characterized by a lower system electrical power, a shorter system lifetime, and an earlier deployment date than any of the missions previously analyzed by Yen and Sauer (Yen and Sauer 1991).

Because preliminary interest has been generated conceming an NEP system employing liquid metal cooled reactor technology and ion electric propulsion having potentially less than a 50-kWe rating, less than 3 year lifetime, and a a deployment date as early as a 1998, it is incumbent that both technology (as well as system) development and demonstration issues between this application and the $100-\mathrm{kWe}$ application be worked in a concurrent manner. The near term deployment date for the lower power application requires technologies that are already mature, implying that some separate technology maturation process will still be required to enable $100-\mathrm{kWe}$ missions. Nevertheless, the early flight option will be extremely useful to verify NEP systems technology, to demonstrate the safety approval process, and to validate as many as possible of the technologies relevant to the more robust outer planetary science mission applications, and therefore provides a path for the development of higher power, future operational NEP capabilities. 


\section{SUMMARY AND CONCLUSIONS}

Building upon the technology heritage available through the SP-100 power and ion electric propulsion programs, the NEP technology project will coordinate, develop, and demonstrate by year 2000 the technologies required for 100 kilowatt-electric (kWe) NEP. Detailed plans, including project content, schedule, and milestones, have been presented for the required ion electric propulsion technology development and demonstration; meanwhile, the SP-100 program is implementing technical plans to develop and demonstrate the required space rated nuclear power technologies. It is clear that closer coordination between organizations responsible for the required space nuclear power and space electric propulsion technologies is necessary for effective, efficient development and utilization of these technologies. NEP system concept definition activities and a possible early flight option for NEP can provide the required focus.

\section{Acknowledgments}

The author wishes to acknowledge Messrs. John Clark, Jim Stone, and Jim Gilland of the LeRC's NPO, Jim Sovey of LeRC's Space Propulsion Technology Division, and John Brophy and Jack Mondt of the Jet Propulsion Laboratory in their contribution to the programmatic exercises which led to the development of this baseline plan. This work was performed "in-bouse" by personnel at LeRC and JPL.

\section{References}

Armijo, J. S. (1992) "SP-100 Overview / Technical Progress," briefing package \#CDRL M027, SP-100 Annual Technical Meeting, Arlington, VA, 16-17 June 1992.

Bennett, G. L. and T. J. Miller (1992) "NASA Program Planning on Nuclear Electric Propulsion," AIAA-92-1557, presented at AIAA Space Programs and Technologies Conference, Huntsville, AL, 24-27 March 1992.

Doherty, M. P. (1991) "Blazing the Trailway: Nuclear Electric Propulsion and its Technology Program Plans," AIAA-91-3441, presented at NASA/ AIAA/ OAI Conference on Advanced Space Exploration Initiative Technologies; Cleveland, OH, 4-6 September 1991.

Greene, J. H. (1992) memorandum regarding "Space Nuclear Power and Propulsion Working Group," NASA Johnson Space Center, Houston, TX, 8 August 1992.

Greene, J. H. and A. R. Newhouse (1992) "Space Nuclear Power and Propulsion: Final Report," National Aeronautics and Space Administration and Department of Energy joint document, Washington, D.C., 15 September 1992.

MIL (1985) "Specification Practices," MIL-STD-490A, 4 June 1985.

NPO (1992) Nuclear Electric Propulsion System Requirements, draft document, revision 003, NASA Lewis Research Center, Cleveland, OH, 14 August 1992.

Sovey, J. S., R. H. Vetrone, S. P. Grisnik, R. M. Myers, and J. E. Parkes (1991) "Test Facilities for High Power Electric Propulsion," AIAA-91-3499, presented at NASA AIAA/OAI Conference on Advanced Space Exploration Initiative Technologies, Cleveland, OH, 4-6 September 1991.

Stone, J. R. and J. S. Sovey (1992) "NASA's Nuclear Electric Propulsion Technology Project," NASA TM 105811, prepared for the 28th Joint Propulsion Conference, Nashville, TN, 6-8 July 1992.

Yen, C. L. and C. G. Sauer (1991) "Nuclear Electric Propulsion for Future NASA Space Science Missions," IEPC91-035, presented at AIDAA/AIAADGLR/JSASS 22nd International Electric Propulsion Conference, Viareggio, Italy, 1417 October 1991. 


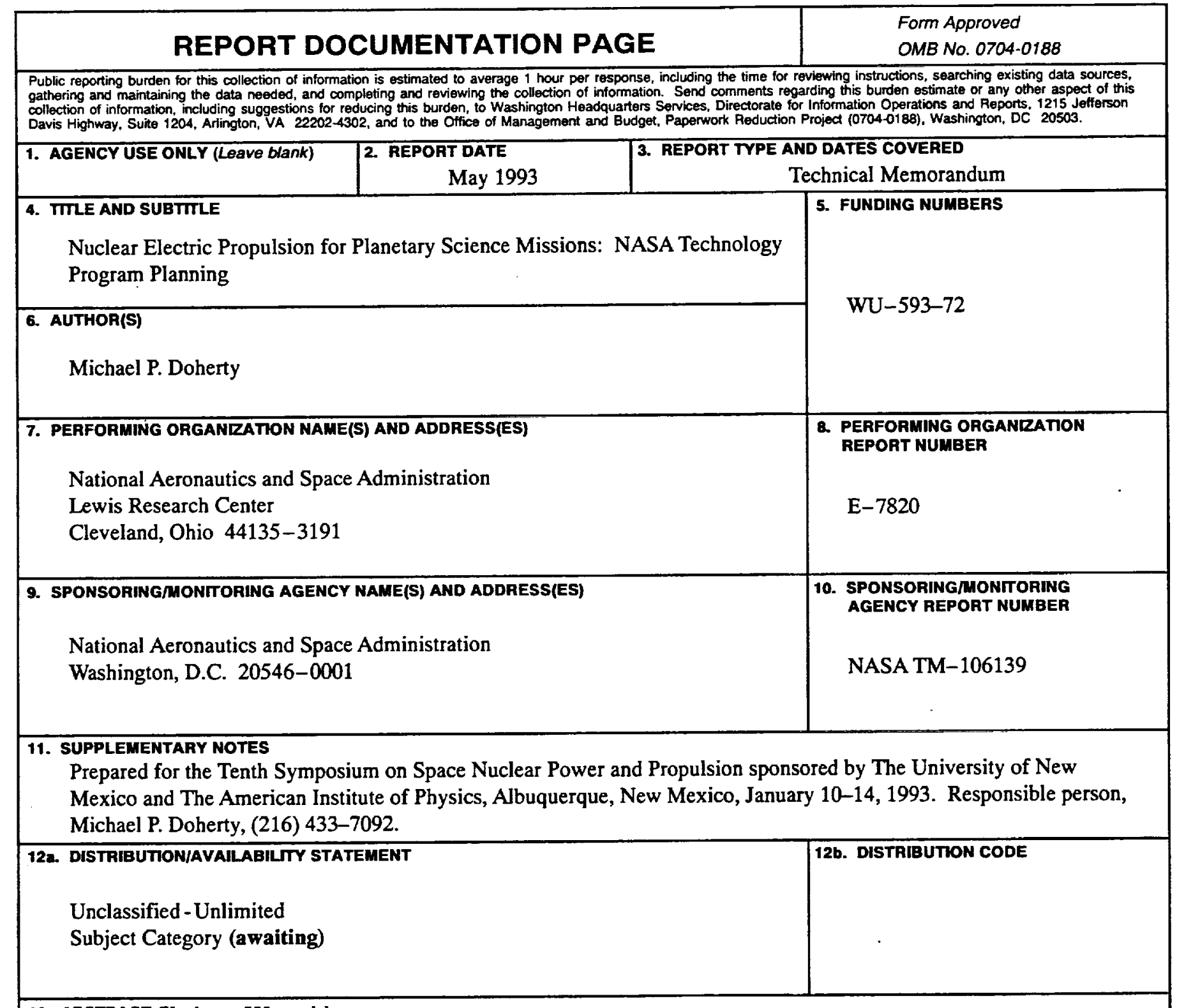

13. ABSTRACT (Maximum 200 words)

This paper presents the status of technology program planning to develop those Nuclear Electric Propulsion technologies needed to meet the advanced propulsion system requirements for planetary science missions in the next century. The technology program planning is based upon technologies with significant development heritage: ion electric propulsion and the SP-100 space nuclear power technologies. Detailed plans are presented herein for the required ion electric propulsion technology development and demonstration. Closer coordination between space nuclear power and space electric propulsion technology programs is a necessity as technology plans are being further refined in light of NEP concept definition and possible early NEP flight activities.

14. SUEJECT TERMS

Nuclear electric propulsion; Ion electric propulsion; Space nuclear power; SP-100; Technology planning

\begin{tabular}{|c|c|c|}
\hline $\begin{array}{c}\text { 17. SECURTY CLASSIFICATION } \\
\text { OF REPORT } \\
\text { Unclassified }\end{array}$ & $\begin{array}{c}\text { 18. SECURTY CLASSIFICATION } \\
\text { OF THIS PAGE } \\
\text { Unclassified }\end{array}$ & $\begin{array}{c}\text { 19. SECURTY CLASSIFICATION } \\
\text { OF ABSTRACT } \\
\text { Unclassified }\end{array}$ \\
\hline
\end{tabular}




\section{,}

